IP $\Vdash$ B

\title{
A nova legislação ambiental brasileira e seus efeitos sobre a reestruturação de nascentes e remanescentes florestais
}

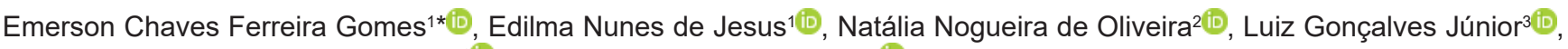 \\ Felipe Gonçalves dos Santos Cabral ${ }^{4(\mathbb{C}}$, Marisa Seoane Rio Resende ${ }^{5(\mathbb{B})}$ \\ ${ }^{1}$ Universidade Federal de Sergipe, Av. Marechal Rondon, s/n, Jardim Rosa Elze, CEP 49100-000, São Cristóvão, SE, Brasil \\ ${ }^{2}$ Centro Universitário UNA, Rua Aimorés, 1451, Lourdes, CEP 30140-071, Belo Horizonte, MG, Brasil \\ ${ }^{3}$ Centro Universitário Metodista Izabela Hendrix, Rua da Bahia, 2020, Lourdes, CEP 30160-012, Belo Horizonte, MG, Brasil \\ ${ }^{4}$ Pontifícia Universidade Católica de Minas Gerais-Betim, Rua Rosário, 1081, Angola, CEP 32604-115, Betim, MG, Brasil \\ ${ }^{5}$ Centro Mineiro de Alianças Intersetoriais, Rua Aimorés, 3018, sala 801, Barro Preto, CEP 30140-073, Belo Horizonte, MG, Brasil
}

"Autor correspondente:

emersonchaves@ymail.com

Termos para indexação:

Conservação de recursos

Gestão ambiental

Avaliação de impacto ambiental

Index terms:

Resource conservation

Environmental management

Environmental impact assessment

Histórico do artigo:

Recebido em 29/06/2016

Aprovado em 11/06/2018

Publicado em 03/08/2018

doi: 10.4336/2018.pfb.38e201601309
Resumo - Foi conduzido um trabalho de diagnóstico ambiental da bacia hidrográfica do Córrego Saraiva, situado no Município de Betim, MG, pela identificação e caracterização das principais nascentes e remanescentes florestais. Além da quantificação da área total dos fragmentos florestais, foi calculada a área passível de recuperação ambiental de ambientes ciliares comparando a legislação ambiental brasileira representada pela Lei Federal $n^{\circ} 4.771$, de 15 de setembro de 1965 com a legislação vigente, Lei Federal $n^{\circ}$ 12.651, de 25 de maio de 2012. Os fragmentos da bacia foram avaliados por métricas de paisagem em Sistema de Informações Geográficas, com base em indicadores ecológicos: índice de circularidade; índice de isolamento; total de área de borda e tamanho médio das manchas. O estado de conservação das nascentes e dos remanescentes florestais na bacia hidrográfica do Córrego Saraiva é crítico. A legislação ambiental brasileira vigente requer menor área total a ser recuperada, comprometendo as funções ecológicas desempenhadas pelos ecossistemas ribeirinhos.

\section{New Brazilian environmental legislation and its effects on restructuring springs and forest fragments}

\begin{abstract}
We performed an environmental diagnosis study of the watershed Saraiva Stream, located in the municipality of Betim, Minas Gerais State, Brazil, through the identification and characterization of the main springs and forest remnants. In addition to quantification of the total area of forest fragments, it was compared the area subject to environmental restoration of riparian areas when applying the Brazilian environmental legislation represented by old Forest Code - Law n ${ }^{\circ} 4.771 / 65$ and the current legislation, Federal Law $n^{\circ} 12.651 / 12$. Fragments were also evaluate through the landscape metrics in Geographic Information System based on ecological indicators: circularity index; isolation index; total border area; and average size of the spots. The springs and forest remnants in the watershed of Saraiva Stream are in critical condition. Current Brazilian environmental legislation demands smaller total area restoration, compromising the ecological functions performed by riverine ecosystems.
\end{abstract}




\section{Introdução}

O conceito de bacia hidrográfica vincula-se à estruturação de um sistema integrado, que apresenta nascentes, divisores de águas e demais cursos d'água organizados hierarquicamente (Santos, 2004). Todas as alterações naturais e antrópicas que venham a interferir neste sistema são passíveis de análise e interpretação e, por este motivo, esses locais são selecionados como unidades de planejamento (Bai et al., 2011; BarreiroLostres et al., 2015).

As nascentes são compartimentos de extrema relevância nas bacias hidrográficas, pois, desses afloramentos dos lençóis freáticos originam-se as fontes de água que irão compor toda a bacia (Lima, 1986). Dessa forma, são ambientes protegidos por lei, sendo consideradas como áreas de preservação permanente (APP) (Galatto et al., 2011).

De acordo com a Lei federal $\mathrm{n}^{\circ} 12.651$ de 25 de maio de 2012, as APP's são áreas cobertas ou não por vegetação nativa, com a função ambiental de preservar os recursos hídricos, a paisagem, a estabilidade geológica e a biodiversidade, facilitar o fluxo gênico de fauna e flora, proteger o solo e assegurar o bem-estar das populações humanas (Brasil, 2012b).

De maneira geral, as áreas de APP's possuem importância para a estabilidade dos ambientes, principalmente por agregar serviços ecossistêmicos fundamentais (Sedell \& Froggatt, 1984; Kominoski et al., 2013). No entanto, mesmo sendo reconhecidos os diversos benefícios promovidos por essas, nesses ambientes são frequentes os impactos antrópicos, como desmatamento visando à construção de moradias, cultivos agrícolas, implantação de vias urbanas, entre outros, e esse quadro indica a necessidade de medidas de restauração de áreas degradadas, como forma de reverter o problema (Ferreira et al., 2011).

O diagnóstico das condições in loco é o primeiro passo para o planejamento da restauração, possibilitando identificar os fatores que possam estar interferindo e provocando a degradação. A partir disso, é possível traçar medidas de restauração, considerando-se todo o sistema da bacia hidrográfica investigada (Felfili et al., 2000; Jesus et al., 2015).

As investigações do contexto da área a ser restaurada complementam o diagnóstico em campo e poderão assegurar maior confiabilidade nas tomadas de decisão. Nesse sentido, são relevantes os dados obtidos por análises de métricas ou índices da paisagem, que de acordo com Metzger (2008) são indicadores que traduzem as condições dos fragmentos, por meio de análises estatísticas que fazem a quantificação dos aspectos da estrutura da paisagem, possibilitando identificar as áreas consideradas prioritárias para os trabalhos de restauração.

Nesse sentido, o presente estudo teve por objetivo analisar os principais impactos ambientais nas nascentes da bacia hidrográfica do Córrego Saraiva, bem como verificar o contexto destas com a aplicação de métricas de paisagem, em vistas a subsidiar o planejamento de ações de restauração em áreas de preservação permanente.

\section{Material e métodos}

\section{Área de estudo}

A pesquisa foi desenvolvida na bacia do Córrego Saraiva, afluente do Rio Betim, município de Betim, MG, situada entre $579.588,58$ E e $584.083,97$ E e 7.792.017,28 N e 7.791.953,77 N, fuso $23 \mathrm{~K}$ do sistema UTM (Universal Transversa de Mercator) e possui área de aproximadamente 3.270 ha (Figura 1). Esse córrego apresenta uma extensão de aproximadamente $12,29 \mathrm{~km}$ e largura de $10 \mathrm{~m}$.

Conforme o Plano Diretor do Município de Betim (Lei municipal $n^{\circ} 5177$, de 10 de agosto de 2011), que estabelece o zoneamento de uso e ocupação do solo, a bacia do Córrego Saraiva possui 14,53\% de sua área em zona urbana, $13,66 \%$ em zona rural e $71,81 \%$ em zona de expansão urbana (Betim, 2011).

Com altitude de $860 \mathrm{~m}$, a temperatura anual média é de $20^{\circ} \mathrm{C}$ e o índice pluviométrico varia entre $1.500 \mathrm{~mm}$ a $2.000 \mathrm{~mm}$ por ano. A região apresenta duas estações bem definidas, sendo um período chuvoso, com altas temperaturas entre os meses de setembro a março, e outro período seco, com temperaturas baixas entre os meses de abril a agosto. Segundo a classificação climática de Köppen, o clima da região é classificado como tropical de altitude ameno e seco (Emater, 2006).

Dentre as atividades econômicas desenvolvidas no limite da bacia, destacam-se a criação de cavalos e de gado, agricultura de subsistência e a extração de brita. Os principais tipos de solos são o Latossolo, Neossolo e Argissolo. Os remanescentes florestais estão inseridos no domínio Mata Atlântica e se apresentam em diversos 


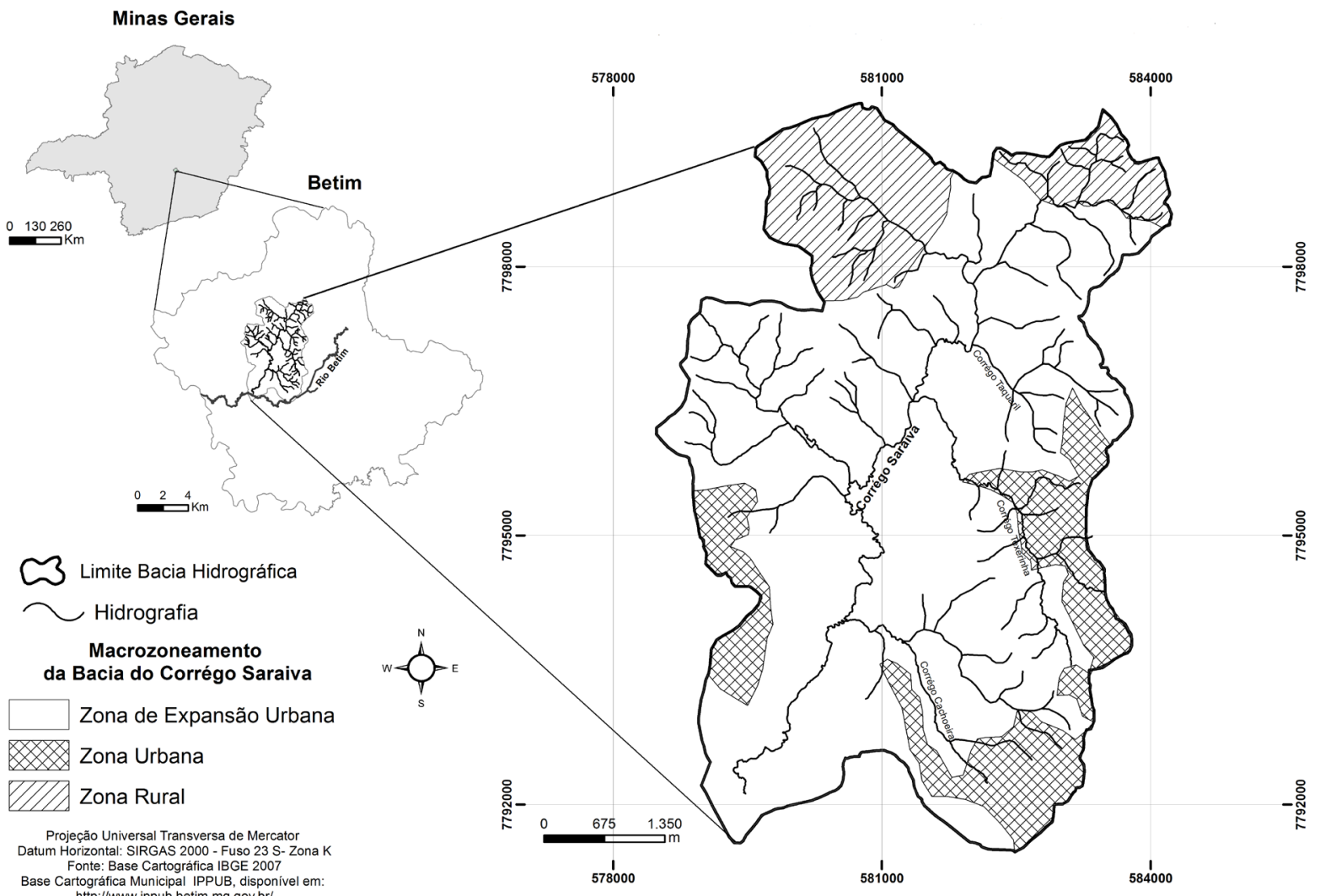

Figura 1. Localização da bacia hidrográfica do Córrego Saraiva, Betim, MG.

tamanhos e formas, bem como distintos estágios sucessionais (Centro Mineiro de Alianças Intersetoriais, 2015).

\section{Procedimentos metodológicos}

Os trabalhos de diagnóstico ambiental foram realizados no período entre novembro de 2013 e agosto de 2015 e dividiram-se em duas etapas. A primeira consistiu em identificar as nascentes e a segunda em caracterizar os remanescentes florestais às margens do leito principal do Córrego Saraiva.

As nascentes foram georreferenciadas utilizando GPS Garmin Oregon 450, segundo a metodologia de Leal (2017). A caracterização das nascentes de acordo com as formas de uso e ocupação do solo e o raio de vegetação existente em torno do olho d'água foi feita com base em Castro (2001), Pinto et al. (2005) e Ferreira et al. (2011). As nascentes foram classificadas pelo tipo de afloramento, que podia ser simples, quando o fluxo ocorria em apenas um local, ou composto, quando o fluxo ocorria em mais de um local. Foi também avaliado o estado de conservação, sendo consideradas preservadas, quando havia presença de vegetação em estágio avançado de sucessão em torno das nascentes com um raio mínimo de $50 \mathrm{~m}$; perturbadas, com raio de vegetação inferior a $50 \mathrm{~m}$, mas que apresentavam bom estado de conservação; ou degradadas, quando não existia o mínimo de vegetação exercendo função de proteção.

As nascentes foram caracterizadas com relação à duração do fluxo em perenes, quando se manifestavam durante todos os meses do ano, e intermitentes, quando se manifestavam apenas no período chuvoso. A Lei $\mathrm{n}^{\mathrm{o}} 12.651$ (Brasil, 2012b) dispõe sobre a proteção da vegetação nativa, e revoga a Lei federal $\mathrm{n}^{\circ} 4.771$ de 15 de setembro de 1965 (Brasil, 1965). Com base nessas duas legislações, foi realizada uma comparação da área total de mata ciliar a ser recuperada nas nascentes degradadas (Brasil, 2012b). 


\section{Caracterização dos fragmentos florestais}

A identificação dos remanescentes florestais ao longo do curso d'água foi feita segundo metodologia utilizada por Ferreira \& Dias (2004). A identificação e delimitação dos remanescentes florestais foram feitos utilizando-se imagens de satélite obtidas pelo Google Earth (Martins \& Rosolen, 2014; Menzori \& Falcoski, 2017). Os alvos identificados foram validados em trabalhos de campo. Para o processamento dos dados utilizou-se o software ArcGIS 10.2.1.

Após a vetorização das manchas florestais, foram comparadas as condições encontradas com as instruções normativas da Lei $n^{\circ} 12.651$ (Brasil, 2012b), verificandose quantitativamente a cobertura vegetal presente e o que seria estimado em cumprimento ao que é determinado legalmente. Os dados dos shapes de localização, hidrografia, dentre outros, utilizados nas análises foram da base do Instituto Brasileiro de Geografia e Estatística (IBGE) (IBGE, 2007).

A delimitação das áreas de preservação permanente (APP's) nas áreas adjacentes ao leito principal do Córrego Saraiva baseou-se nos parâmetros instituídos na Lei $n^{\circ} 12.651$ (Brasil, 2012b), que define como - APP, em zonas rurais ou urbanas, as faixas marginais de $30 \mathrm{~m}$ para os cursos d'água que possuem menos de $10 \mathrm{~m}$ de largura, como é o caso do Córrego Saraiva. Contudo, a recuperação das áreas de APP que sofreram intervenções ilícitas na zona rural é diferenciada conforme o tamanho das propriedades, definidos em módulos fiscais.

Segundo o Instituto Nacional de Colonização e Reforma Agrária (INCRA) (Incra, 2015) o valor de um módulo fiscal para a cidade de Betim é de 7 ha. Assim, para propriedades com área de até um módulo fiscal, é necessário recuperar $5 \mathrm{~m}$ de APP; com área superior a um até dois módulos fiscais, $8 \mathrm{~m}$ de APP; com área superior a dois até quatro módulos fiscais, $15 \mathrm{~m}$; com mais de quatro até dez módulos fiscais, $20 \mathrm{~m}$; demais casos, a recuperação deverá ser de, no mínimo, $30 \mathrm{~m}$. Para áreas localizadas em zona urbana, considera-se a faixa com largura mínima de $15 \mathrm{~m}$ de cada lado do curso d'água.

O Plano Diretor classifica que o Córrego Saraiva está inserido em duas regiões: região norte, com 2,03 km de extensão, localizada na zona rural; e as regiões central e sul da bacia, com 10,26 km de extensão, situadas na zona de expansão urbana. Foi realizado o cálculo da área dos remanescentes florestais e o quanto que deveria existir nas áreas urbanizadas na faixa de $15 \mathrm{~m}$, de acordo com a Lei $n^{\circ} 12.651$ (Brasil, 2012b). As propriedades localizadas na zona rural possuem áreas acima de quatro módulos fiscais, o que determina a recuperação de $30 \mathrm{~m}$ de faixa ciliar. Além da identificação das APP's em campo, observou-se o uso e ocupação do solo nestas áreas, bem como inadequação de atividades presentes.

\section{Análise dos fragmentos por meio das métricas de paisagem}

Foram selecionados indicadores ecológicos (Finotto, 2011), para a análise da estrutura da paisagem da bacia do Córrego Saraiva. Os indicadores utilizados foram: índice de circularidade, que apresenta medida adimensional, sendo que o valor do índice se aproxima de um quando os fragmentos tendem a ter formas arredondadas, e quando se distanciam de um, formas mais alongadas; índice de isolamento $(\mathrm{m})$, que indica a distância média entre os fragmentos na área; total de área de borda (m), que apresenta o perímetro total de todas as bordas na classe; e tamanho médio das manchas (ha), que indica o tamanho médio dos fragmentos em relação à bacia.

Os dados (shapes) dos fragmentos foram processados no programa Arcgis 10.1, com a extensão gratuita Patch analyst 4.0 (Rempel, 1999). Foram utilizadas as versões Patch (para dados vetoriais) e patch grid (dados convertidos em formato raster), sendo os indicadores citados obtidos a partir das opções disponibilizadas no programa.

\section{Resultados e discussão}

Foram diagnosticadas 31 nascentes na bacia do Córrego Saraiva (Figura 2). Muitas áreas apresentavam topografia acidentada de difícil acesso, impossibilitando a localização das nascentes. A presença de condomínios instalados na área de estudo comprometeu a identificação das nascentes, visto que muitos terrenos e propriedades são utilizados como sítios de lazer e os proprietários não se encontravam presentes durante as visitas técnicas.

Com relação ao tipo de afloramento, 17 nascentes foram classificadas como simples e 14 como compostas. Em relação ao fluxo, 25 nascentes apresentaram fluxo perene ou contínuo ao longo do ano e 6 apresentaram fluxo apenas em algum período na estação chuvosa.

Quanto ao estado de conservação, apenas uma nascente $(3,23 \%)$ apresentava um raio de $50 \mathrm{~m}$ de vegetação ciliar em torno do olho d'água. Vinte e duas nascentes $(70,97 \%)$ apresentavam algum grau de perturbação e 8 nascentes $(25,81 \%)$ não apresentavam 
qualquer vegetação arbórea execercendo a função de proteção das mesmas (Tabela 1).

A pastagem se destaca como principal atividade impactante na área em estudo, sendo essa classe de uso do solo presente em 24 nascentes registradas $(77,42 \%)$. Para fins de representatividade, as nascentes foram numeradas de um a 31. Com exceção da nascente 22, os animais são criados soltos no pasto e não há nenhuma delimitação e impedimento de acesso dos animais nas áreas das nascentes. Observou-se que grande parte do volume da água das nascentes é utilizada para dessedentação dos animais e irrigação das hortas e pomares das propriedades.

A pecuária intensiva é uma das atividades que causa sérios impactos ambientais negativos aos ecossistemas tropicais (Soares et al., 2011). O pastejo contínuo é o sistema de exploração do solo mais empregado nas áreas estudadas (Figura 3). A ausência de cercamento das APP's contribuem para a perda da qualidade de água, comprometendo a utilização desse recurso hídrico para uso doméstico.

A conversão de áreas de vegetação nativa em áreas de pastagens promove diversos impactos negativos aos biomas naturais (Barbosa et al., 2008, Lososová et al., 2011). Nas áreas em estudo, a principal espécie vegetal utilizada nas pastagens é a gramínea do gênero Brachiaria (Figura 4). Essa espécie exótica apresenta alto grau de competição e de dispersão, produzindo grande quantidade de biomassa, encobrindo o solo e comprometendo a germinação de sementes de arbustos e espécies arbóreas nativas da região (Bianco et al., 2005; Matos \& Pivello, 2009).

Em estudos desenvolvidos por Galatto et al. (2011), identificou-se que em áreas de APP a ocupação urbana suprimiu trechos de vegetação que deveriam estar preservados e esse conflito de ocupação pode comprometer tanto a disponibilidade quanto a qualidade dos recursos hídricos.

Assim, a exemplo dos trabalhos anteriores realizados por Castro (2001), Pinto et al. (2005) e Ferreira et al. (2011), baseados na Lei no 4.771 (Brasil, 1965), a área total de mata ciliar que deveria existir nas 30 nascentes degradadas seria de aproximadamente $235.619 \mathrm{~m}^{2}$, considerando os $50 \mathrm{~m}$ de raio de revegetação nas atividades de recuperação ambiental.

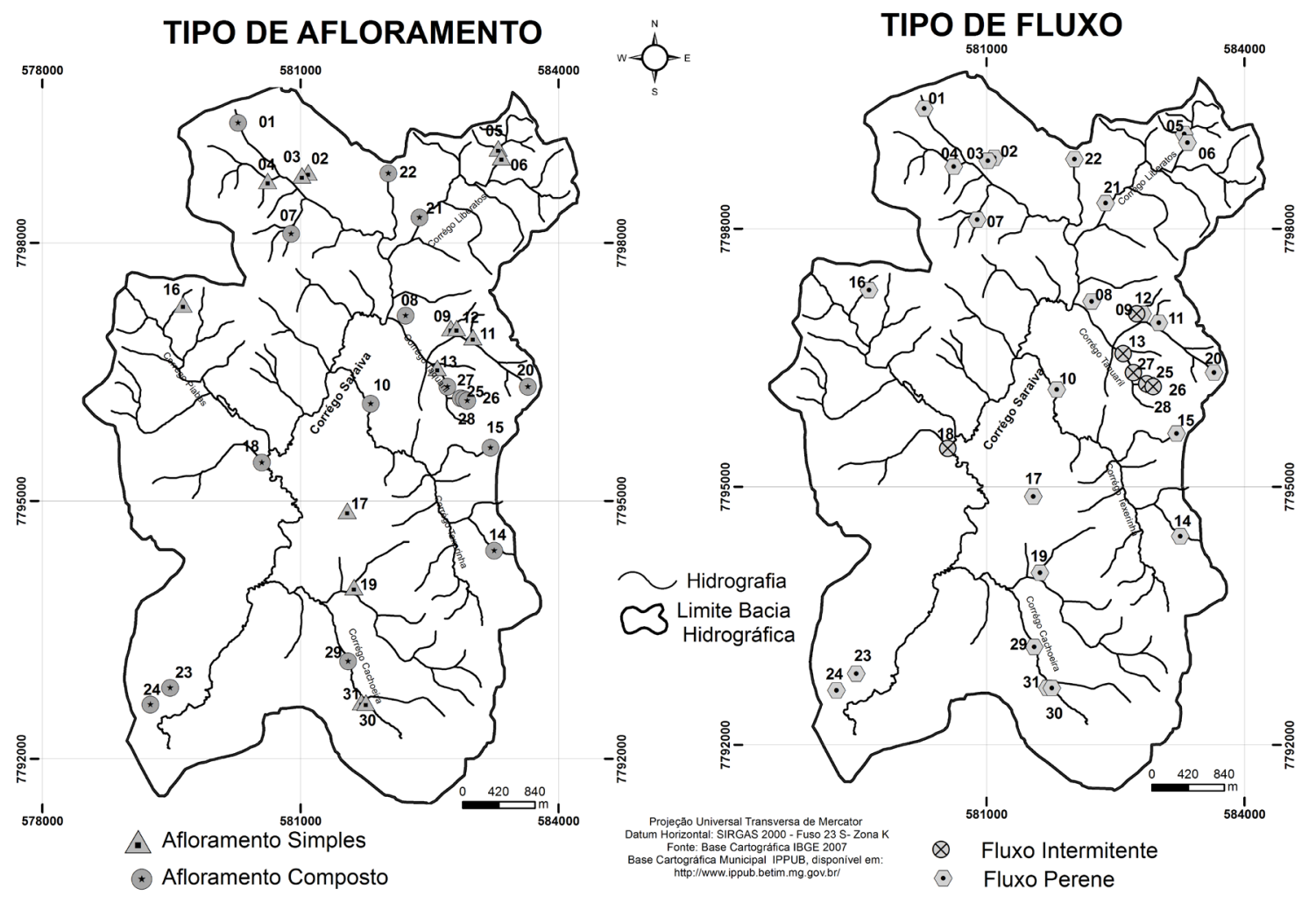

Figura 2. Nascentes georreferenciadas na bacia hidrográfica do Córrego Saraiva, Betim, MG, 2015. 
Tabela 1. Classificação das nascentes quanto ao estado de conservação na bacia do Córrego Saraiva, Betim, MG, 2015.

\begin{tabular}{|c|c|c|c|c|c|c|c|c|c|}
\hline \multirow[b]{2}{*}{ Nascente } & \multicolumn{2}{|c|}{$\begin{array}{l}\text { Coordenadas } \\
\text { (Fuso 23k) }\end{array}$} & \multirow[b]{2}{*}{ Alt (m) } & \multicolumn{3}{|c|}{ Conservação } & \multicolumn{3}{|c|}{ Formas de uso do solo } \\
\hline & Latitude & Longitude & & $\begin{array}{c}\text { Preservada } \\
\text { (Mata ciliar } \\
\text { com raio de } \\
50 \mathrm{~m})\end{array}$ & $\begin{array}{c}\text { Perturbada } \\
\text { (Mata ciliar } \\
\text { com raio } \\
\text { inferior a } \\
50 \mathrm{~m} \text { ) }\end{array}$ & $\begin{array}{c}\text { Degradada } \\
\text { (Ausência } \\
\text { de Mata } \\
\text { ciliar) }\end{array}$ & Pastagem & Agricultura & Urbanizada \\
\hline 1 & $7.799 .395,21$ & $580.276,39$ & 858 & & $\mathrm{X}$ & & $X$ & & \\
\hline 2 & $7.798 .822,12$ & $581.092,23$ & 805 & & $X$ & & $\mathrm{X}$ & & \\
\hline 3 & $7.798 .787,25$ & $581.018,99$ & 802 & & $X$ & & $X$ & & \\
\hline 4 & $7.798 .721,10$ & $580.619,47$ & 810 & & & $\mathrm{X}$ & & $\mathrm{X}$ & \\
\hline 5 & $7.799 .099,33$ & $583.300,67$ & 858 & & $\mathrm{X}$ & & $\mathrm{X}$ & & \\
\hline 6 & $7.798 .997,47$ & $583.337,15$ & 846 & & & $\mathrm{X}$ & $\mathrm{X}$ & & \\
\hline 7 & $7.798 .105,07$ & $580.894,49$ & 809 & & $\mathrm{X}$ & & $\mathrm{X}$ & & \\
\hline 8 & $7.797 .152,33$ & $582.222,52$ & 780 & & & $\mathrm{X}$ & $\mathrm{X}$ & & \\
\hline 9 & $7.797 .009,15$ & $582.748,78$ & 817 & & & $\mathrm{X}$ & $\mathrm{X}$ & & \\
\hline 10 & $7.796 .128,75$ & $581.818,59$ & 775 & & & $\mathrm{X}$ & $\mathrm{X}$ & & \\
\hline 11 & $7.796 .904,60$ & $583.005,71$ & 805 & & $\mathrm{X}$ & & $\mathrm{X}$ & & \\
\hline 12 & $7.797 .009,15$ & $582.814,98$ & 809 & & $\mathrm{X}$ & & $\mathrm{X}$ & & \\
\hline 13 & $7.796 .547,71$ & $582.592,40$ & 787 & & $\mathrm{X}$ & & $\mathrm{X}$ & & \\
\hline 14 & $7.794 .421,00$ & $583.254,00$ & 818 & & $\mathrm{X}$ & & & & $\mathrm{X}$ \\
\hline 15 & $7.795 .617,65$ & $583.210,85$ & 844 & & $\mathrm{X}$ & & & & $\mathrm{X}$ \\
\hline 16 & $7.797 .285,40$ & $579.636,95$ & 829 & & $\mathrm{X}$ & & $\mathrm{X}$ & & \\
\hline 17 & $7.794 .849,61$ & $581.429,37$ & 781 & & $\mathrm{X}$ & & & & $\mathrm{X}$ \\
\hline 18 & $7.795 .444,17$ & $580.553,36$ & 761 & & & $\mathrm{X}$ & $\mathrm{X}$ & & \\
\hline 19 & $7.793 .998,65$ & $581.624,05$ & 776 & & $\mathrm{X}$ & & $\mathrm{X}$ & & \\
\hline 20 & $7.796 .325,47$ & $583.644,96$ & 856 & & $\mathrm{X}$ & & $\mathrm{X}$ & & \\
\hline 21 & $7.798 .294,48$ & $582.385,49$ & 801 & & $\mathrm{X}$ & & $\mathrm{X}$ & & \\
\hline 22 & $7.798 .807,49$ & $582.023,70$ & 895 & $\mathrm{X}$ & & & $\mathrm{X}$ & & \\
\hline 23 & $7.792 .824,43$ & $579.486,95$ & 725 & & $\mathrm{X}$ & & $\mathrm{X}$ & & \\
\hline 24 & $7.792 .591,00$ & $579.268,00$ & 727 & & & $\mathrm{X}$ & $\mathrm{X}$ & & \\
\hline 25 & $7.796 .194,00$ & $582.864,58$ & 822 & & & $\mathrm{X}$ & $\mathrm{X}$ & & \\
\hline 26 & $7.796 .182,10$ & $582.903,00$ & 795 & & $\mathrm{X}$ & & & $\mathrm{X}$ & \\
\hline 27 & $7.796 .325,39$ & $582.709,22$ & 821 & & $\mathrm{X}$ & & & $\mathrm{X}$ & \\
\hline 28 & $7.796 .163,59$ & $582.941,14$ & 839 & & $\mathrm{X}$ & & & $\mathrm{X}$ & \\
\hline 29 & $7.793 .134,02$ & $581.554,63$ & 769 & & $\mathrm{X}$ & & $\mathrm{X}$ & & \\
\hline 30 & $7.792 .659,60$ & $581.709,14$ & 773 & & $\mathrm{X}$ & & $\mathrm{X}$ & & \\
\hline 31 & $7.792 .655,68$ & $581.761,09$ & 773 & & $\mathrm{X}$ & & $\mathrm{X}$ & & \\
\hline
\end{tabular}

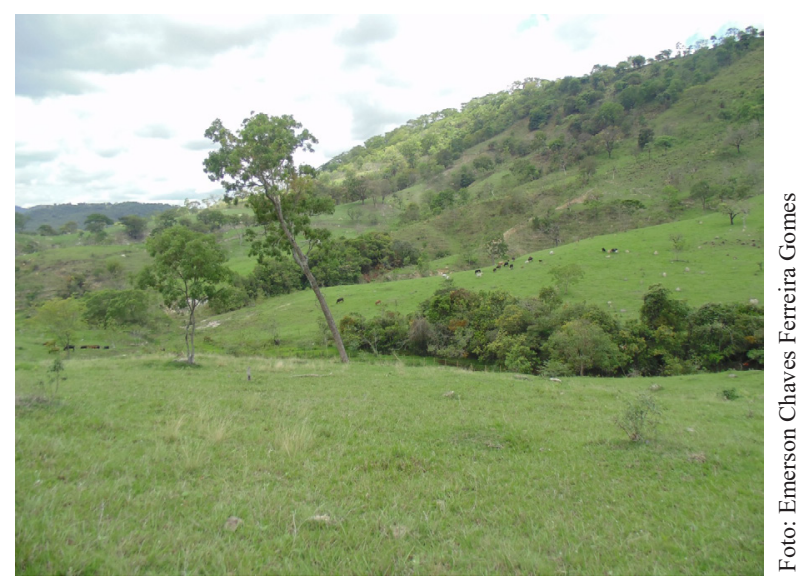

Figura 3. Área de pastagem em torno da nascente georreferenciada número 11. Propriedade localizada na zona de expansão urbana na bacia hidrográfica do Córrego Saraiva, Betim, MG, em 11/11/2014.

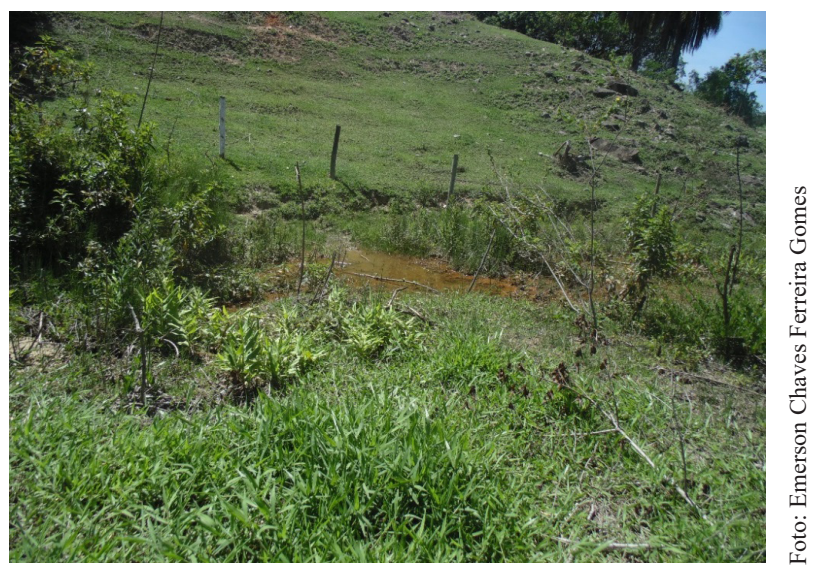

Figura 4. Presença de gramínea do gênero Brachiaria em área de preservação permanente (nascente 6). Propriedade localizada na zona rural na bacia hidrográfica do Córrego Saraiva, Betim, MG, em 05/07/2014. 
Algumas mudanças com relação à proteção dos ecossistemas ribeirinhos foram realizadas através da Lei $n^{\circ} 12.651$ (Brasil, 2012b), entre elas a determinação que em áreas consolidadas até 22 de julho de 2008 em torno de nascentes perenes, o raio de vegetação a ser recuperada deveria ser de $15 \mathrm{~m}$, além de retirar a proteção de nascentes intermitentes. Sendo assim, a legislação ambiental atual prevê que a área de mata ciliar a ser recuperada, considerando-se apenas as 24 nascentes perenes degradadas, deverá ser de $16.964 \mathrm{~m}^{2}$, área essa bem inferior a $235.619 \mathrm{~m}^{2}$, se consideradas a Lei $\mathrm{n}^{\circ}$ 4.771 (Brasil, 1965).

Algumas áreas apresentam histórico de degradação decorrente do uso de máquinas e tratores, visando alteração da topografia local para implementação de loteamentos ou o desenvolvimento de atividades agrossilvipastoris. Provavelmente, a ausência de gestão e de planejamento urbano promoveram o soterramento e desvio da posição geográfica do olho d'água de várias nascentes.

$\mathrm{Na}$ nascente 17 houve o represamento do volume de água e a área ciliar é utilizada para a recreação da população local. As nascentes 23 e 24 são utilizadas para a dessedentação de animais da propriedade. Nessas três nascentes verificou-se vazão de água nos períodos de seca e de chuva. Entretanto, no período amostrado não foram observados canais de drenagem. Possivelmente, o uso da água nessas áreas compromete o fluxo da água.

Foram registrados 33 remanescentes florestais em várias formas e tamanhos e em diferentes estados de conservação. A soma da área de todos remanescentes, considerando $30 \mathrm{~m}$ de faixa ciliar em ambos os lados do córrego, é de 32,64 ha de mata ciliar $(45,06 \%)$. Nesse cálculo foram desprezadas as áreas ocupadas por bambuzais, já que essa vegetação não exerce as mesmas funções ecológicas quando comparada à vegetação nativa. De acordo com a Lei $\mathrm{n}^{\circ} 4.771$ (Brasil, 1965) a quantidade de mata ciliar total que deveria estar presente, considerando os $30 \mathrm{~m}$ de faixa nas duas margens, foi calculada em, aproximadamente, 72,44 ha.

Outra considerável alteração realizada na legislação ambiental brasileira foi com relação à faixa de vegetação a ser recuperada, medida a partir da borda da calha do leito regular e não do seu nível mais alto. Considerando que os rios no nosso país apresentam alterações significativas do leito durante os períodos de cheias (Alho, 2008; Silva et al., 2011), a redução dos valores de faixa ciliar a ser recuperada no trecho urbano e rural pode comprometer a conservação dos recursos hídricos na bacia hidrográfica em estudo.

A partir da nascente principal, registrada como a de número 1, os primeiros 2,03 km de extensão do Córrego Saraiva inseridos na zona rural, embora caracterizado como o trecho menos urbanizado, é fortemente impactado pelas atividades de equinocultura e pecuária. Nesse trecho foi realizado o desvio do leito do córrego por estruturas de concreto subterrâneas para a construção de uma estrada vicinal. Esse histórico de degradação gerou um passivo ambiental da ordem de 4,81 ha de áreas ciliares a serem recuperadas.

Para o trecho seguinte (aproximadamente 10,26 km) caracterizado como o mais urbanizado, localizado na zona de expansão urbana, houve redução da área total a ser recuperada, visto que a Lei $\mathrm{n}^{\circ} 4.771$ (Brasil, 1965) considerava que deveriam ser recuperados 25,24 ha de mata ciliar, respeitando os $30 \mathrm{~m}$ a partir do leito maior, e com a Lei $\mathrm{n}^{\mathrm{o}} 12.651$ (Brasil, 2012b), o total a ser recuperado se restringe a 11,14 ha, pois a faixa de recuperação é de $15 \mathrm{~m}$ a partir do leito regular. No entanto, o Plano Diretor do município de Betim (Lei municipal $n^{\circ}$ 5.177) (Betim, 2011) demarcou algumas áreas ribeirinhas, inseridas nesse trecho, como áreas de risco, visto que há aumento do volume e da largura do leito do córrego no período chuvoso.

Para Nery et al. (2013) e Soares-Filho et al. (2014), a redução das áreas de APP, instituída pelas alterações na legislação ambiental vigente através da Lei $n^{\circ}$ 12.651 (Brasil, 2012b), trouxe impactos negativos ao ambiente, pela diminuição de locais que abrigam alta biodiversidade. Logo, se a cobertura de áreas preservadas já era deficitária quando se considerava legislações anteriores, a redução da faixa a ser protegida fragiliza mais ainda esse contexto, principalmente no tocante à manutenção dos recursos hídricos.

Com um total de 106 fragmentos, a bacia do Córrego Saraiva apresentou o índice de circularidade $=2,00$, o que reflete a possibilidade de formas mais alongadas e complexas para os fragmentos da área estudada. Resultados semelhantes foram encontrados por Silva et al. (2015a), ao avaliarem o estado de conservação atual da paisagem na região das cidades de Ouro Preto, Ouro Branco e Mariana, em Minas Gerais, correspondendo às áreas situadas no alto das bacias dos rios das Velhas, do Carmo, Gualaxo do Sul e Ribeirão da Colônia. Os autores obtiveram índice calculado $(\mathrm{MSI})>1(3,035)$, o que indicou a presença de formas adversas para a preservação da biodiversidade. 
Segundo Almeida et al. (2011), a irregularidade da forma dos fragmentos contribui para que cresçam as probabilidades de que estas áreas tenham maior influência de fatores externos, o que compromete a sobrevivência das espécies mais sensíveis. Logo, este fator deverá ter influência na bacia, principalmente pelo predomínio de pequenos fragmentos, com tamanho médio bastante reduzido em 6,7 ha, que são ainda mais vulneráveis em relação às alterações do entorno.

Esta condição é semelhante à verificada por Pirovani et al. (2015), que caracterizaram fragmentos florestais em uma bacia hidrográfica no Espírito Santo, onde identificaram maioria de fragmentos pequenos $(74,5 \%)$, sendo, de acordo com os mesmos, indicativo de redução das áreas conservadas. Além disso, segundo esses autores, fragmentos reduzidos configuram-se em habitats com menores possibilidades de se assegurar viabilidade de espécies ao longo do tempo, mesmo se tratando de um padrão comum em florestas da Mata Atlântica.

Com relação ao total de área de borda (TE), foram verificados $1.407,0 \mathrm{~m}$, decorrente do grande número de pequenos fragmentos. De acordo com Silva et al. (2015b), essa característica é frequente em áreas onde os fragmentos são em sua maioria pequenos e irregulares, tendendo a apresentar maiores perímetro de borda (TE).

$\mathrm{O}$ índice de isolamento, verificado com a métrica (MPI), apresentou valores médios de $1.375 \mathrm{~m}$ de grau de isolamento para toda a bacia estudada. $\mathrm{O}$ isolamento e a fragmentação dos remanescentes comprometem a conservação e a sustentabilidade da vegetação ripária, pois interrompem vários processos ecológicos (Magnago et al., 2012; Sekercioglu et al., 2015), e este processo é perceptível na bacia do Córrego Saraiva.

As regiões sul e sudeste da bacia estão mais próximas do centro urbano, e sujeitas à especulação imobiliária. É possível observar a presença de vários condomínios instalados e em processo de efetivação ao longo de toda a área da bacia, principalmente nas áreas próximas ao leito do Córrego Saraiva e de seus afluentes, contribuindo para a redução da área florestada nativa.

O Plano Diretor do município apresenta como um grande problema a caracterização de aproximadamente $72 \%$ da área da bacia Córrego Saraiva como zona de expansão urbana. Essa definição favorece as agressões ambientais, ou seja, potencializa ações contrárias à legislação ambiental brasileira. Sendo assim, necessitase a reformulação e readequação das APPs no Plano Diretor do município de Betim, visando à conservação e manutenção dos recursos naturais na Bacia Hidrográfica do Córrego Saraiva.

Foi considerado que o estado de conservação dos remanescentes florestais e das nascentes registradas na bacia hidrográfica do Córrego Saraiva está crítico, sendo necessária a adoção de um planejamento ambiental urbano e rural para subsidiar a gestão do uso e ocupação do solo e a implantação de programas de recuperação ambiental.

Os órgãos ambientais federais, estaduais e municipais devem divulgar e incentivar a regularização ambiental das propriedades rurais conforme o Decreto $\mathrm{n}^{\circ} 7.830 \mathrm{de}$ 17 de outubro de 2012, que dispõe sobre o Sistema de Cadastro Ambiental Rural (Brasil, 2012a). Ao realizar o cadastro, o proprietário, assume o compromisso de preservar e de realizar a recomposição florestal de áreas degradadas. Tais programas deverão incluir atividades que impossibilitem o acesso dos animais na faixa ciliar prevista em lei, a realização do plantio de espécies arbóreas nativas em áreas de baixa resiliência ambiental e o reflorestamento das áreas de recarga e topo de morro, que são importantes para a infiltração da água no solo, mantendo a vazão das nascentes, além de desenvolver corredores ecológicos, visando encurtar as distâncias entre os remanescentes florestais.

\section{Conclusões}

Foi possível verificar que a conservação da vegetação ciliar na bacia hidrográfica do Córrego Saraiva, em Betim, MG se encontra em estado crítico de conservação. O histórico de uso e ocupação do solo promoveu fortes impactos negativos nas 30 nascentes identificadas $(96,7 \%)$.

A ocupação desordenada ao longo do leito do Córrego Saraiva suprimiu aproximadamente 54,94\% da vegetação ciliar. Os impactos verificados podem ser caracterizados pela retirada total ou parcial da vegetação arbórea, visando áreas para construção civil, além das áreas adjacentes aos cursos d'água, que são utilizadas para a dessedentação de gado e/ou cavalos.

De forma geral, a bacia apresenta um contexto de fragmentação, com maioria de pequenos fragmentos com formas irregulares e isolados. $\mathrm{O}$ isolamento e a fragmentação dos remanescentes florestais, além da presença de bambuzais, comprometem a sustentabilidade das matas de galeria. 
As alterações na legislação ambiental das áreas de proteção dos remanescentes de florestas nativas promoveram uma redução significativa das áreas a serem recuperadas na vegetação ciliar. Tais alterações levam à discussão sobre os fatores positivos da legislação vigente, em relação à preservação das áreas de mata ciliar.

\section{Agradecimentos}

A Restaura Ambiental e ao Centro Mineiro de Alianças Intersetoriais (Cemais), pelo apoio, e a Petróleo Brasileiro S.A. (Petrobras), pelo financiamento desse trabalho.

\section{Referências}

Alho, C. J. R. Biodiversity of the Pantanal: response to seasonal flooding regime and to environmental degradation. Brazilian Journal of Biology, v. 68, n. 4, p. 957-966, 2008.

Almeida, F. S. et al. Estratégicas para a conservação da biodiversidade biológica em florestas fragmentadas. Ambiência, v. 7, n. 2, p. $367-$ 382, 2011. DOI: 10.5777/ambiencia.2011.02.01rb.

Bai, Y. et al. Spatial characteristics between biodiversity and ecosystem services in a human-dominated watershed. Ecological Complexity, v. 8, p. 177-183, 2011. DOI: 10.1016/j.ecocom.2011.01.007.

Barbosa, E. G. et al. Allelopathic evidence in Brachiaria decumbens and its potential to invade the Brazilian Cerrados. Brazilian Archives of Biology and Technology, v. 51, p. 825-831, 2008. DOI: $10.1590 / \mathrm{S} 1516-89132008000400021$.

Barreiro-Lostres, F. et al. Sediment delivery and lake dynamics in a Mediterranean mountain watershed: human-climate interactions during the last millennium (El Tobar Lake record, Iberian Range, Spain). Science of The Total Environment, v. 15 p. 506-519, 2015. DOI: 10.1016/j.scitotenv.2015.06.123.

Brasil. Decreto ${ }^{0} \mathbf{7 . 8 3 0}$, de 17 de outubro de 2012a. Dispõe sobre o Sistema de Cadastro Ambiental Rural, o Cadastro Ambiental Rural, estabelece normas de caráter geral aos Programas de Regularização Ambiental, de que trata a Lei $\mathrm{n}^{\circ} 12.651$, de 25 de maio de 2012, e dá outras providências. Disponível em: $<\mathrm{http}$ :/www.planalto.gov. br/ccivil_03/_ato2011-2014/2012/decreto/D7830.htm>. Acesso em: 30 dez. 2017.

Brasil. Lei $\mathbf{n}^{\mathbf{0}} \mathbf{4 . 7 7 1}$, de 15 de setembro de 1965. Institui o novo Código Florestal. Disponível em: <http://www.planalto.gov.br/ ccivil_03/Leis/14771.htm>. Acesso em: $30 \mathrm{dez} .2017$.

Brasil. Ministério do Meio Ambiente. Lei no 12.651 de 25 de maio de 2012b. Dispõe sobre a proteção da vegetação nativa ... Disponível em: <http://www.planalto.gov.br/ccivil_03/_ato2011-2014/2012/lei/ 112651.htm>. Acesso em: 30 dez. 2017.

Betim. Diretoria de Políticas Públicas. Lei n ${ }^{0}$ 5.177, de 10 de agosto de 2011. Dispõe sobre a revisão do Plano Diretor do município de Betim. Disponível em: <http:/www.dpurb.betim.mg.gov.br/site/ index.php/legislacao-2/plano-diretor>. Acesso em: 4 maio 2016.
Bianco, S. et al. Crescimento e nutrição mineral de capim braquiária. Planta Daninha, v. 23, p. 423-428, 2005. DOI: 10.1590/S010083582005000300005.

Castro, P. S. Recuperação e conservação de nascentes. Viçosa, MG: Centro de Produções Técnicas, 2001. 84 p.

Centro Mineiro de Alianças Intersetoriais. Diagnóstico socioambiental da Microbacia Hidrográfica do Córrego Saraiva. 2015. Disponível em: $<$ http://www.aguasdosaraiva.org.br $>$. Acesso em: 28 mar. 2016.

Emater (Minas Gerais). Betim: caracterização dos ecossistemas. Belo Horizonte, 2006. Disponível em: <http://www.betim.mg.gov. br/ARQUIVOS_ANEXO/relatoriobetim;0724280503;20070213. pdf>. Acesso em: 20 ago. 2016.

Felfili, J. M. et al. Changes in floristic composition of cerrado sensu stricto in Brazil over a nine year period. Journal of Tropical Ecology, v. 16, n. 4, p. 579-590, 2000.

Ferreira, D. A. C. \& Dias, H. C. T. Situação da mata ciliar do Ribeirão São Bartolomeu em Viçosa, M.G. Revista Árvore, v. 28, n. 4, p. 617-623, 2004. DOI: 10.1590/S0100-67622004000400016.

Ferreira, R. A. et al. Nascentes da sub-bacia hidrográfica do rio Poxim, Estado de Sergipe: da degradação à restauração, Revista Árvore, v. 35, n. 2, p. 265-277, 2011. DOI: 10.1590/S010067622011000200011.

Finotto, F. Landscape assessment: the ecological profile. In: Cassatella, C. \& Peano, A. (Ed.). Landscape indicators: assessing and monitoring landscape quality. Dordrecht: Springer, 2011. p. 47-76.

Galatto, S. L. et al. Diagnóstico ambiental de nascentes no município de Criciúma, Santa Catarina. Revista de Ciências Ambientais, v. 5, n. 1, p. 39-56, 2011.

IBGE. Base cartográfica municipal IPPUB. 2007. Disponível em: $<$ http://www.ippub.betim.mg..gov.br/>. Acesso em: 20 set. 2015.

Incra (Brasília, DF). Índices básicos 2013 por município. 2015. Disponível em: <http:/www.incra.gov.br/estrutura-fundiaria/ regularizacao-fundiaria/indices-cadastrais $>$. Acesso em: 10 jun. 2015.

Jesus, E. N. et al. Estrutura dos fragmentos florestais da bacia hidrográfica do Rio Poxim-SE, como subsídio à restauração ecológica. Revista Árvore, v. 39, n. 3, p. 467-474, 2015. DOI: 10.1590/0100-67622015000300007.

Kominoski, J. S. et al. Forescasting functional implications of global changes in riparian plant communities. Frontiers in Ecology and the Environment, v. 11, p. 423-432, 2013. DOI: 10.1890/120056.

Leal, M. S. et al. Caracterização hidroambiental de nascentes. Revista Ambiente \& Água, v. 12, n. 1, p. 146-155, 2017. DOI: 10.4136/ ambi-agua.1909.

Lima, W. de P. Princípios de hidrologia florestal para o manejo de bacias hidrográficas. Piracicaba: ESALQ/USP, 1986. 242 p.

Lososová, Z. et al. Biotic homogenization of Central European urban floras depends on residence time of alien species and habitat types. Biological Conservation, v. 145, p. 179-184, 2011. DOI: 10.1016/j. biocon.2011.11.003.

Pesq. flor. bras., Colombo, v. 38, e201601309, p. 1-10, 2018 
Magnago, L. F. S. et al. Os processos e estágios sucessionais da Mata Atlântica como referência para restauração florestal. In: Martins, S. V. (Org.). Restauração ecológica de ecossistemas degradados. Viçosa, MG: Ed. UFV, 2012. p. 69-100.

Martins, F. P. \& Rosolen, V. S. Caracterização morfológica de uma catena (Latossolo Gleissolo) no campo de murundu do Córrego da Fortaleza, Chapada Uberlândia-Uberaba, Uberlândia-MG. Caminhos de Geografia, v. 15, n. 52, p. 186-200, 2014.

Matos, D. M. S. \& Pivello, V. R. O impacto das plantas invasoras nos recursos naturais de ambientes terrestres: alguns casos brasileiros. Ciência e Cultura, v. 61, p. 27-30, 2009.

Menzori, I. D. \& Falcoski, L. A. N. Mapeamento e análise das áreas de preservação permanente e dos corredores de integração ecológica de Araraquara, SP. Ambiente Construído, v. 17, n. 2, p. 7-20, 2017. DOI: $10.1590 / \mathrm{s} 1678-86212017000200143$.

Metzger, J. P. Como restaurar a conectividade em paisagens fragmentadas? In: Kageyama, P. Y. et al. Restauração ecológica de ecossistemas naturais. Botucatu: FEPAF, 2008. p. 307-330.

Nery, C. V. M. et al. Aplicação do Novo Código Florestal na avaliação das Áreas de Preservação Permanente em topo de morro na subbacia do Rio Canoas no município de Montes Claros/MG. Revista Brasileira de Geografia Física, v. 6, n. 6, p. 1673-1688, 2013.

Pinto, L. V. A. et al. Estudo da vegetação como subsídios para propostas de recuperação das nascentes da bacia hidrográfica do Ribeirão Santa Cruz, Lavras, MG. Revista Árvore, v. 29, n. 5, p. 775-739, 2005. DOI: 10.1590/S0100-67622005000500013.

Pirovani, D. B. et al. Análise da paisagem e mudanças no uso da terra no entorno da RPPN Cafundó, ES. Cerne, v. 21, n. 1, p. 27-35, 2015. DOI: $10.1590 / 01047760201521011182$.
Rempel, R. S. Natural disturbance analysis \& planning tools. Edmonton, AB: Sustainable Forest Management Network, 1999. $16 \mathrm{p}$.

Santos, R. F. Planejamento ambiental: teoria e prática. São Paulo: Oficina de Textos, 2004. 184 p.

Sedell, J. R. \& Froggatt, J. L. Importance of streamside forests to large rivers: the isolation of the Willamette River, Oregon, U. S. A., from its floodplain by snagging and streamside forest removal. Internationalen Verein Limnologie, v. 22, p. 1828-1834, 1984.

Sekercioglu, C. H. et al. Tropical countryside riparian corridors provide critical habitat and connectivity for seed-dispersing forest birds in a fragmented landscape. Journal of Ornithology, v. 156, p. 343-353, 2015. DOI: 10.1007/s10336-015-1299-x.

Silva, A. C. et al. Variação espaço-temporal da dinâmica da comunidade arbórea em 465 fragmentos de floresta aluvial em Minas Gerais. Cerne, v. 17, n. 4, p. 465-471, 2011. DOI: 10.1590/S010477602011000400004.

Silva, R. A. et al. Avaliação da cobertura florestal na paisagem de Mata Atlântica no ano de 2010, na região de Ouro Preto - MG. Cerne, v. 21, n. 2, p. 301-309, 2015a. DOI: 10.1590/01047760201521021539.

Silva, S. F. et al. Análise espacial dos fragmentos florestais da subbacia hidrográfica do Rio da Prata em Ibiraçu e Aracruz - ES, Brasil. Vértices, v. 17, n. 1, p. 121-132, 2015b. DOI: 10.5935/18092667.20150008.

Soares-Filho, B. et al. A. Cracking Brazil's Forest Code. Science, v. 344, p. 363-364, 2014. DOI: 10.1126/science. 1246663.

Soares, V. P. et al. Mapeamento de áreas de preservação permanentes e identificação dos conflitos legais de uso da terra na bacia hidrográfica do ribeirão São Bartolomeu - MG. Revista Árvore, v. 35, n. 3, p. 555-563, 2011. DOI: 10.1590/S0100-67622011000300018. 